\title{
THE PREVALENCE AND NATURE OF SEXUAL HARASSMENT IN THE WORKPLACE: A MODEL FOR EARLY IDENTIFICATION AND EFFECTIVE MANAGEMENT THEREOF
}

\author{
A RAMSAROOP \\ S BRIJBALL PARUMASUR \\ brijballs@ukzn.ac.za \\ Discipline of Human Resource Management \\ School of Management \\ Faculty of Management Studies \\ University of KwaZulu-Natal \\ (Westville Campus)
}

\begin{abstract}
This study investigates the prevalence and nature of sexual harassment and, assesses the impact of supervisory relations, levels of interaction, appearance and personality and types of behaviour. The study was undertaken at a tertiary institution using a sample of 74 employees, drawn by means of simple random sampling. Data was collected using a self-developed questionnaire, which was statistically tested and, analysed using descriptive and inferential statistics. The results indicate that the sub-dimensions of the study impact significantly on sexual harassment. Based on the findings, a model for early identification and effective management of sexual harassment in the workplace was generated.
\end{abstract}

Key words:

Sexual harrassment, quid pro quo, hostile work environment, socio sexual behaviour, sexual harrassment policy, occupational sex segregation, supervisory relations, levels of interaction, appearance and personality, types of behaviours

The purpose of any organisation is goal accomplishment, survival, effectiveness and organisational growth. Attaining these goals depend on the four factors of production, namely, entrepreneurship, capital, natural resources and labour. Human capital is a vital resource and, an integral ingredient for organisational effectiveness is sound interpersonal relations. These relationships are however, compromised by the most controversial, complex and widespread human resource problem, that is, sexual harassment (Carrell, Elbert, Hatfield, Grobler, Marx \& Van De Schyf, 2000). Sexual harassment is a serious infringement on the rights of employees within an organisation and victims are forced to deal with unpleasant and humiliating experiences, which often result in emotional and psychological trauma. Furthermore, sexual harassment creates an offensive, intimidating and hostile working environment for the victim, which ultimately impedes productivity and social interactions within the organisation.

Perhaps, the most frequently asked question about sexual harassment tries to determine which specific behaviours constitute sexual harassment. Much research to date, has actually been removed from the issue of sexual harassment by focusing more on the entire spectrum of sociosexual behaviour at the workplace (Studd \& Gattiker, 1991, cited in Buss \& Neil, 1996). Such research approaches the study of sexual harassment by analysing which aspects of these patterns of behaviour are unwanted. In defining sexual harassment, the sexual advance, request for sexual favours, sexually verbal or physical conduct must be "unwelcome". In other words, the complaining individual must show that he or she did not want, invite, solicit or encourage the sexual conduct in order to prove that sexual harassment actually occurred. A truly consensual sexual relationship or sexual conduct in which the alleged victim willingly participated or set in motion, may not be considered unwelcome and hence, is not sexual harassment (Roumell \& Danlene, 1999). Additionally, further contention occurs in the fact that when the courts consider whether sexual conduct was unwelcome, they look at all circumstances and concentrate on the alleged victim, not the alleged offender's intent. Reid (2004) broadly describes sexual harassment as a form of unlawful sex discrimination. A spectrum of behavioural patterns may signify sexual harassment (Figure 1).

\begin{tabular}{|c|c|c|c|c|c|c|}
\hline Visual & Verbal & Written & Touching & Power & Threats & Force \\
\hline Ogling & $\begin{array}{l}\text { Requests } \\
\text { for dates }\end{array}$ & $\begin{array}{l}\text { Love } \\
\text { poems }\end{array}$ & $\begin{array}{l}\text { Violating } \\
\text { space }\end{array}$ & $\begin{array}{l}\text { Relation- } \\
\text { ships }\end{array}$ & $\begin{array}{l}\text { Quid pro } \\
\text { quo }\end{array}$ & Rape \\
\hline Staring & $\begin{array}{l}\text { Questions } \\
\text { about } \\
\text { personal } \\
\text { life }\end{array}$ & $\begin{array}{l}\text { Love } \\
\text { letters }\end{array}$ & Patting & $\begin{array}{l}\text { Using } \\
\text { position } \\
\text { to request } \\
\text { dates, sex, } \\
\text { etc. }\end{array}$ & Demands & $\begin{array}{l}\text { Physical } \\
\text { assault }\end{array}$ \\
\hline Posters & $\begin{array}{l}\text { Lewd } \\
\text { com- } \\
\text { ments }\end{array}$ & $\begin{array}{l}\text { Obscene } \\
\text { Poems }\end{array}$ & Grabbing & & $\begin{array}{l}\text { Loss of } \\
\text { job }\end{array}$ & \\
\hline $\begin{array}{l}\text { Maga- } \\
\text { zines }\end{array}$ & $\begin{array}{l}\text { Dirty/ } \\
\text { sexual } \\
\text { jokes }\end{array}$ & $\begin{array}{l}\text { Obscene } \\
\text { letters }\end{array}$ & Pinching & & $\begin{array}{l}\text { Selection } \\
\text { process }\end{array}$ & \\
\hline \multirow[t]{2}{*}{ Flyers } & Whistling & Cards & Caressing & & & \\
\hline & & & Kissing & & & \\
\hline \multicolumn{7}{|c|}{$\leftarrow \begin{array}{cc}\text { Offensive Conduct } \\
\text { (May be illegal) }\end{array} \quad$ (Illegal in all cases) } \\
\hline \multicolumn{4}{|c|}{$\begin{array}{l}\text { Individual perceptions and } \\
\text { reactions determine } \\
\text { Harassment. } \\
\text { Behaviours unwanted by recipient } \\
\text { are harassment. } \\
\text { Behaviours may not be intended } \\
\text { to harass, but that is often the } \\
\text { result. } \\
\text { - Illegal if the result is perceived } \\
\text { as harassment. }\end{array}$} & \multicolumn{3}{|c|}{$\begin{array}{l}\text { Behaviours are intentional; } \\
\text { goal is to intimidate, harass or } \\
\text { hurt another person. }\end{array}$} \\
\hline
\end{tabular}

Figure 1: Sexual harassment - A spectrum of behavioural patterns Carrell, M.R., Elbert, N.F., Hatfield, R.D., Grobler, P.A., Marx, M. \& Van De Schyf, S. (2000). Human Resource Management in South Africa. South Africa: Mills Litho. 64.

Sexual harassment can be divided into two types, namely, quid pro quo and hostile environment sexual harassment. With quid pro quo sexual harassment, a supervisor or a manager, requests or demands sexual favours in exchange for some employment benefit. Bravo and Cassedy (1992) states that Quid Pro Quo cases are the most clear-cut. Quid Pro Quo harassment operates as a form of on-the-job blackmail (Renzetti, Edleson \& Bergen, 
2001). However, determining a link between the unwelcome, improper sexual conduct and the employer's action is imperative to proving quid pro quo sexual harassment.

Hostile environment sexual harassment is a far more common form of harassment than sexual blackmail. In the study of graduate women, $80 \%$ of respondents who experienced harassment reported hostile environment experiences (Renzetti et al., 2001). A significant proportion of the case law has dealt with hostile environment sexual harassment and has hence, been shaped and crystallised by this form of harassment. In establishing a prima facie case of harassment, a plaintiff must show that unwelcome conduct of a sexual nature has affected his/her terms or conditions of employment; either it has had an adverse effect on his/her work performance or created a hostile working environment (Achampong, 1995). This can be proven based on the frequency of the discriminatory conduct, its severity, whether it was physically threatening or humiliating and whether it unreasonably interrupted work performance (Fair Employment Practices Guidelines, 2006). This serves as a baseline for qualifying hostile environment claims. However, much controversy exists in proving a sexual harassment case because a significantly adverse employment action against the complainant must have occurred, and the improper conduct by the alleged harasser must have been severe or pervasive enough for a court to find that it created a hostile work environment (Neil, 2006).

Sexual harassment is not only directed to women or even limited to behaviour between members of the opposite sex (Unit for Research \& Gender Studies, 1998). Female employees are however, far more exposed to harassment than their male colleagues (Fitzgerald, 1993; Landrine \& Klonoff, 1997; Wayne, 2000; Jackson \& Newman, 2004). Women are susceptible to sexual harassment at work mainly as a result of:-

- Horizontal segregation, which refers to the clustering of working women in a small number of job categories that are traditionally associated with women such as nurses, teachers and secretaries (Unit for Research \& Gender Studies, 1998).

- Vertical stratification means that women tend to be employed in low ranking positions and are dependentupon the approval and goodwill of males for hiring, retention and advancement (Unit for Research and Gender Studies, 1998).

Likewise, Neil (2006) reflects that women sometimes commit harassment against men, and same-sex harassment also occurs.

\section{Horizontal segregation}

In South Africa, the participation of women in the formal economy has increased from $41 \%$ in 1960 to just under $45 \%$ in 1985 (Unit for Research \& Gender Studies, 1998) to 47.8\% in 2003 (South Africa Survey, 2003/2004). Furthermore, the South African economically active male population increased from $53.06 \%$ in 2001 to $55.37 \%$ in 2003 whilst the South African economically active female population decreased from $46.94 \%$ in 2001 to $44.63 \%$ in 2003 . In addition, women have moved into specific sectors and specific jobs within these sectors. In 2002 , $62 \%$ of males were professionally qualified whilst there were only $38 \%$ of females in this category. In addition, in 2002 , $64 \%$ of males occupied semi-skilled jobs with discretionary decision-making whilst only $36 \%$ of women fitted this category. Furthermore, in 2003, 43.84\% of working women were employed in the informal sector (South Africa Survey, 2003/2004). Hence, within specific sectors women were clustered in particular job types; notably amongst these were secretaries, typists, clerks, receptionists and bank tellers (South Africa Survey, 2001/2002). Hence, at a macro-level, there is strong evidence of horizontal clustering, with women typically employed in 'women's jobs', that is, in job categories noted for their sex typing and workplace settings characterised by sex segregation (Bassoon, 1999). According to Jackson and Newman (2004), evidence that sexual harassment remains entrenched in the workplace may be largely due to the persistence of occupational sex segregation. Furthermore, Schultz (1998: 1760) adds that "hostile work environment harassment is both engendered by, and further entrenches, the sex segregation of work".

\section{Vertical stratification}

At a micro-level, vertical stratification by gender is also evidenced in the South African workplace. In 2002, only $12 \%$ of females were employed in top management whilst this category included $88 \%$ of males (South Africa Survey, 2003/2004). Furthermore, in 2002 , $82 \%$ of males occupied senior management posts, whilst only $12 \%$ of females were employed in this category (South Africa Survey, 2003/2004). Clearly, despite significant advances, a number of women perform low status jobs where their work is organised and evaluated by men (Kelly, 1989, cited in Renzetti et al., 2001). Sex role spillover has been shown to occur when the gender composition of the work group or work role set is either predominantly male or female, as opposed to being gender balanced (Gutek \& Morasch, 1982). Women in traditionally male or female occupations have been found to experience more sexual harassment than women in gender-neutral occupations (Gutek \& Morasch, 1982). Similarly, the results of Jackson and Newman (2004) demonstrate that men who work primarily with women are more likely to receive unwanted sexual attention than those who work primarily with other men.

With highly patriarchal institutions, women who break into new occupations and work settings or who challenge the superiority of men responsible for social, economic or organisational power over them, are visible targets for sexualised hostility (Bravo \& Cassedy, 1992; Renzetti et al., 2001). However, cross-gender contact only predicted amounts of sexual harassment for women in "blue-collar" occupations where a physical "macho" culture pervaded as compared to "white-collar" managerial occupations (Raging \& Squander, 1992, cited in Stockdale, 1996; Jackson \& Newman, 2004). When routinely practiced, sexual harassment does more than gratify the few individuals who perpetrate it; it also serves to enforce the patriarchal status quo (Wise \& Stanley, 2000, cited in Renzetti et al., 2001).

Most sexual harassment cases involve women in traditional occupations, with lower incomes. According to the Equal Opportunities Commission (2000a), women remain disadvantaged as compared to men as a result of occupational segregation, which leaves them concentrated in lower skilled and lower paid jobs with less access to vocational training and education. Furthermore, Skaine (1996) indicates that sexual harassment victims held lower positions in the occupational hierarchy. Skaine (1996) found that of women victims reporting sexual harassment, $51 \%$ were trainees and $47 \%$ earned a low income. Seventy nine percent of these victims named their co-workers and other employees as the harasser, while $40 \%$ named a supervisor. The amount of risk a woman assumes varies according to the type of environment in which she performs her work. Women who work in highly sexualised environments experience more harassment than those who do not (Defour, 1990, cited in Renzetti et al., 2001).

In the United Kingdom, the Equal Opportunities Commission (2000b: 2) estimates that "sexual harassment happens to about half of all women in the workforce at some time in their working lives". Similarly, in the United States, Fitzgerald, cited in Bimrose (2004), deduced that sexual harassment has recently been recognised as a social problem of enormous proportions, with as many as one in every two women being subjected to some form of harassment during her academic or working life. There may be a greater incidence of harassment among working women in South Africa. Bravo and Cassedy (1992) maintain that the percentage of women in South Africa who have been subjected to some form of harassment during their employment may even be as high as 70\% (Bravo \& Cassedy, 1992). As a manager, one has to be perceptive about these relationships in order to be able to assess any workplace misconduct, including sexual 
harassment. The difference could be that sexual harassment may not take place if senior managers are around to observe it (Roumell \& Danlene, 1999).

Victims of sexual harassment can experience a wide range of emotional reactions, namely, humiliation, self-doubt, selfblame, loss of self-confidence, anger and severe depression (Fritzgerald, 1993; Landrine \& Klonoff, 1997). They do not always recognise the connections between the physical symptoms and the stress they are experiencing. Sexual harassment cases often reduce productivity and teamwork and idea generation, all of which impact on organisational effectiveness. It often leads to lower morale and reduced employee loyalty and settlements. Organisations are tarnished by the exposure and negativity of sexual harassment. When sexual harassment charges were brought by a female employee against CEO of Toyota Motor North America, Inc, Toyota lost face as soon as the news hit the newspapers. But Toyota's culture proved itself in the sex scandal. Toyota replaced the CEO, announced special training for executives to help them prevent harassment, reviewed conduct policies (USA Today, 2006), launched procedures for reporting sexual harassment charges and thereby, displayed that there can be no excuse when an employee is sexually harassed, intimidated and humiliated in the workplace, especially by the boss (Automotive News, 2006). Clearly, Toyota wanted to be perceived such that they take the issues of workplace discrimination and sexual harassment seriously and have no tolerance for any behaviour of this nature. Such media coverage can have drastic implications for organisations. Government and other organisations often cancel contracts with companies that have sexual harassment problems (Eberharat, 1995). Family members suffer along with the harassment victim, experiencing emotional as well as financial losses (Bravo \& Cassedy, 1992).

Evidently, the management of sexual harassment in the workplace necessitates nurturing a value system and advocating norms of behaviour, developing a culture of mutual respect, ensuring a safe and healthy work environment, emphasizing ethical behaviour and the Standard Code of Conduct. Whilst these serve as preventative measures to sexual harassment, reactive measures to sexual harassment may include having effective complaint and reporting channels, observing workplace activities and behaviours, monitoring the occurrence of gender hostility and discrimination and ensuring punishment for sexual harassment offenders.

Undoubtedly, sexual harassment in the workplace is detrimental to both the employee and the organisation and, has to be combated with urgency. One strategy to do so, is to implement an effective sexual harassment policy, which elucidates clear procedures for the prevention, and management, of sexual harassment. However, a sexual harassment policy is insufficient to prevent its occurrence. Strategies and remedies for dealing with sexual harassment become imperative in the workplace. The organisation has to ensure that everyone in the workplace has the right tools and awareness to deal with sexual harassment head-on (McElroy, 1996). This study aims to generate a model for the early identification, and effective management of, sexual harassment by studying four key dimensions, which have the potential to impact on the prevalence and nature of sexual harassment in the workplace, namely, supervisory relations, levels of interaction, appearance and personality and types of behaviour.

\section{Objectives of the study}

The study aims to:

- Assess the prevalence and nature of sexual harassment in the organisation.

- Evaluate the extent to which the dimensions of the study (supervisory relations, levels of interaction, appearance and personality, types of behaviour) determine the prevalence and nature of sexual harassment.
- Assess the biographical profiles of the employees (age, marital status, tenure, race, education, job status, gender) in terms of the dimensions impacting on sexual harassment.

- To assess the perceived impact of the dimensions of the study (supervisory relations, levels of interaction, appearance and personality and, types of behaviour) on the prevalence and nature of sexual harassment.

- Generate a model, based on the findings of the study, for early identification of sexual harassment and the effective management thereof.

\section{RESEARCH DESIGN}

\section{Participants/respondents}

The population for the study consisted of 150 academic and non-academic staff in the Human Sciences at the then called University of Durban-Westville (before the merger). The data was collected at a time when the prevalence of sexual harassment and the number of reported cases were increasing in both organisational and academic environments. The reason for including academic staff in the study was that reported cases of sexual harassment indicated that in many cases harassers were well educated. The study was undertaken on a sample of 74 subjects, drawn using quota sampling to ensure an almost balanced representation of both males and females ( 41 females, 33 males). The subjects were then drawn using the simple random sampling technique. The sample size was considered to be sufficient to get a sense of the perceived impact of the key dimensions of the study on sexual harassment. The adequacy of the sample was further determined using the Kaiser-MeyerOlkin Measure of Sampling Adequacy (0.629) and the Barlett's Test of Spherecity (Chi-square $=3093.77, p=0.000$ ), which respectively indicated suitability and significance. The results indicate that the normality and homoscedasticity preconditions are satisfied.

\section{Measuring instrument}

Data was collected through the use of self-developed, personally administered questionnaires. The purpose of using this method was to give the subjects adequate time to think before responding to statements regarding the prevalence and nature of sexual harassment. The questionnaire comprised on two sections. The first section consisted of biographical information measured on a nominal scale, relating to gender, age, marital status, tenure and level of education and were selected based on target characteristics known to have the potential to influence the prevalence of sexual harassment. The second section comprised of a series of closed-ended questions measured on a 5 point Likert Scale ranging from strongly disagree (1) to strongly agree (5) based on the four key dimensions that have the potential to impact on the prevalence and nature of sexual harassment:-

- Supervisory relations - Supervisors and managers may pose as prime harassers. This study aims to determine whether rank and the current patriarchal institution, which can still largely be described as having horizontal and vertical segregation, increases the prevalence and magnitude of sexual harassment. Eight items were used to assess whether supervisors use power and control to demand sexual favours, whether they engage in sexually charged comments/ gender-related insults/constant leering/unwelcomed sexual advances/sexual teasing and unwanted touching and whether they request sexual favours in exchange for job-related benefits.

- Levels of interaction - The amount of time spent between the genders could be a key factor impacting on the prevalence and nature of sexual harassment. With women building careers in traditionally male-dominated workplaces and professions, the nature of interaction needs to be explored. In the survey, five items were used to assess whether individuals present themselves in sexually seductive or 'suggestive' ways 
to the opposite sex, whether verbal and physical incidences and request for sexual relationships were noted and whether there is social pressure for men/women to flirt with each other at work.

- Appearance and personality - The study aims to assess whether subjects believe that appearance and personality of individuals plays a significant role in increasing the prevalence of sexual harassment. Thus, three items were used to determine whether attractiveness enhances the potential for sexual harassment, whether sex role stereotyping exists and whether sexual advances are made to physically attractive individuals.

- Types of behaviour - Fourteen items were included in the study to determine which of the entire spectrum of sociosexual behaviour exists in the academic institution. These behaviours include gender-related insults, complimentary sexual looks/ gestures and a spectrum of behavioural patterns ranging from staring, verbal comments, dirty/sexual jokes, touching, sexual propositioning, placing demands to physical assault.

\section{Procedure}

The questionnaire was designed after the literature review was conducted to ensure the correct identification of the key dimensions of the study and to ensure that the items in the questionnaire were relevant. This ensured face and content validity. Thereafter, an in-house pretesting process was undertaken, by circulating the questionnaire to colleagues in the field of work, to obtain feedback on the suitability of the items. A pilot test of the questionnaire was conducted on 10 subjects, as a trial run to detect if any weaknesses in the design and instrumentation existed, using the same protocols and procedures as that designated for the actual data collection process. The questionnaire was easily understood and no changes were required. The questionnaire was personally administered to each respondent and a detailed explanation of the instructions was given. A total of 74 correctly completed questionnaires were received.

\section{Statistical analysis}

The validity of the questionnaire was assessed using Factor Analysis. A principal component analysis was used to extract initial factors and an iterated principal factor analysis was performed using SPSS with an Orthogonal Varimax Rotation. Four factors with latent roots greater than unity were extracted from the factor loading matrix and only items with loadings $>0.5$ were considered to be significant. Furthermore, when items were significantly loaded on more than one factor, only those with the highest value were selected. The four factors identified confirm the four dimensions used in this study to determine the prevalence and nature of sexual harassment. The reliability of the questionnaire was determined using Cronbach's Coefficient Alpha (Alpha $=0.9633$ ), which indicated a very high level of internal consistency of the items and hence, a very high degree of reliability. It also reflects that the dimensions reliably determine the prevalence and nature of sexual harassment.

Descriptive statistics, using frequency analyses, percentages, mean analyses and standard deviations were utilised to assess perceptions of the four dimensions impacting on sexual harassment. Inferential statistics used to test the hypotheses included correlation, analysis of variance (ANOVA), t-test and multiple regression.

\section{RESULTS}

The prevalence of sexual harassment was assessed by asking subjects to respond to items relating to the key dimensions using a 5 point Likert scale and descriptive statistics were thereby generated (Table 1).
Table 1 indicates staff perceptions of the nature of supervisorysubordinate relations, the levels of interaction amongst staff, and the influence of appearance and personality and types of behaviour in terms of the prevalence of sexual harassment. The results reflect that the aforementioned occur in the workplace in varying degrees, which in descending level of occurrence are:-

- Sexual advances made to attractive and seductive individuals (appearance and personality) $(5.2 \div 15 \times 100=34.67)$

- Interaction incorporating verbal and physical harassment (levels of interaction) $(8.5 \div 25 \times 100=34)$

- The occurrence of sexually suggestive behaviour and sexual behaviour patterns (types of behaviour) (23.31 70 $\times 100=33$ )

- Supervisors using their power to demand sexual favours and to make unwanted sexual advances (supervisory relations) $(9.68 \div 40 \times 100=24.2)$

TABLE 1

Descriptive Statistics: KeY Dimensions DeTERMining THE PREVALENCE OF SEXUAL HARASSMENT

\begin{tabular}{lccccccc}
\hline Variable & N & Range & $\begin{array}{c}\text { Mini- } \\
\text { mum }\end{array}$ & $\begin{array}{c}\text { Maximum } \\
\text { attainable } \\
\text { score }\end{array}$ & Mean & $\begin{array}{c}\text { Std. } \\
\text { Devia- } \\
\text { tion }\end{array}$ & Variance \\
\hline $\begin{array}{l}\text { Supervisory } \\
\text { relations }\end{array}$ & 74 & 14 & 8 & 40 & 9,68 & 3,197 & 10,222 \\
$\begin{array}{l}\text { Levels of } \\
\text { interaction }\end{array}$ & 74 & 16 & 5 & 25 & 8,50 & 3,826 & 14,637 \\
$\begin{array}{l}\text { Appearance } \\
\text { and }\end{array}$ & 74 & 12 & 3 & 15 & 5,20 & 2,914 & 8,493 \\
personality & & & & & & & \\
$\begin{array}{l}\text { Types of } \\
\text { behaviour }\end{array}$ & 74 & 35 & 14 & 70 & 23,31 & 10,121 & 102,436 \\
\hline
\end{tabular}

Figure 2 graphically indicates the extent to which the aforementioned key dimensions occur in the workplace concerned and therefore, reflects the prevalence and nature of sexual harassment.

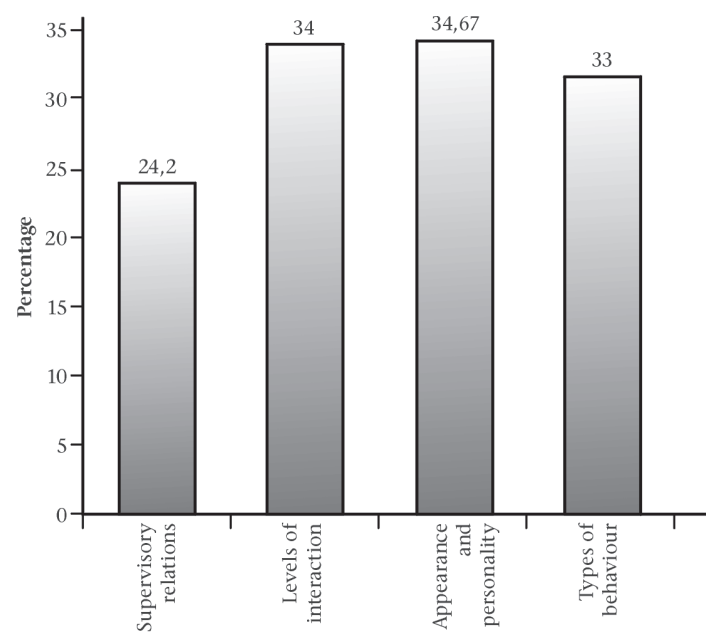

Figure 2: The prevalence of key dimensions and sexual harassment

\section{Hypothesis 1}

There exists significant intercorrelations among the key dimensions of the study (supervisory relations, levels of interaction, appearance and personality, types of behaviours) used to determine the prevalence and nature of sexual harassment (Table 2). 
TABLE 2

INTERCORRELATIONS AMONGST THE KEY DIMENSIONS DETERMINING THE PREVALENCE AND NATURE OF SEXUAL HARASSMENT

\begin{tabular}{|c|c|c|c|c|c|}
\hline Variable & $\mathrm{r} / \mathbf{p}$ & $\begin{array}{c}\text { Supervisory } \\
\text { relations }\end{array}$ & $\begin{array}{c}\text { Levels of } \\
\text { interaction }\end{array}$ & $\begin{array}{l}\text { Appearance } \\
\text { and } \\
\text { personality }\end{array}$ & $\begin{array}{c}\text { Types of } \\
\text { behaviours }\end{array}$ \\
\hline
\end{tabular}

Supervisory $\mathrm{r}$

$\begin{array}{lll}\text { relations } & \text { p } & 1,000\end{array}$

Levels of $\quad \mathrm{r} \quad 0,422$

$\begin{array}{lllll}\text { Appearance } & \mathrm{r} & 0,342 & 0,893 & \mathbf{1 , 0 0 0}\end{array}$

personality

$\begin{array}{lllll}\text { Types of } & r & 0,411 & 0,932 & 0,857\end{array}$

$\begin{array}{lllll}\text { behaviours p } 0,000^{*} & 0,000^{*} & 0,000^{*} & 1,000\end{array}$

$* p<0,01$

Table 2 indicates that there exists significant intercorrelations amongst all the dimensions of the study used to determine the prevalence and nature of sexual harassment in the workplace at the $1 \%$ level of significance. Hence, hypothesis 1 may not be rejected. Significant intercorrelations amongst the dimensions indicate the interrelated nature of the behaviours occurring in the work environment which have the potential to snowball and have a larger influence on the prevalence of sexual harassment at work.

\section{Impact of biographical variables}

The biographical profiles of subjects were assessed in terms of their perceptions of the occurrence of the key dimensions used to determine sexual harassment in the workplace.

\section{Hypothesis 2}

There is a significant difference in the perceptions of employees varying in biographical data (age, marital status, tenure, race, gender and education) regarding the key dimensions used to determine the prevalence and nature of sexual harassment in the workplace (Table 3 and Table 4).

\section{TABLE 3}

Anova - Biographical data And dimensions of the Study USED to DETERMINE THE PREVALENCE AND NATURE OF SEXUAL HARASSMENT

\begin{tabular}{|c|c|c|c|c|c|c|c|c|c|c|}
\hline \multirow[t]{2}{*}{$\begin{array}{l}\text { Var- } \\
\text { iable }\end{array}$} & \multicolumn{2}{|c|}{ Age } & \multicolumn{2}{|c|}{$\begin{array}{c}\text { Marital } \\
\text { status }\end{array}$} & \multicolumn{2}{|c|}{ Tenure } & \multicolumn{2}{|c|}{ Race } & \multicolumn{2}{|c|}{ Education } \\
\hline & $\mathbf{F}$ & p & F & $\mathbf{P}$ & F & p & $\mathbf{F}$ & p & $\mathbf{F}$ & p \\
\hline $\begin{array}{l}\text { Super- } \\
\text { visory } \\
\text { rela- } \\
\text { tions }\end{array}$ & 0,662 & 0,621 & 1,889 & 0,122 & 2,241 & 0,073 & 0,902 & 0,410 & 2,128 & 0,104 \\
\hline $\begin{array}{l}\text { Levels } \\
\text { of inter- } \\
\text { action }\end{array}$ & 2,656 & 0,040 * & 1,513 & 0,208 & 1,263 & 0,293 & 3,789 & 0,027 * & 1,048 & 0,377 \\
\hline $\begin{array}{l}\text { Appear- } \\
\text { ance } \\
\text { and } \\
\text { person- } \\
\text { ality }\end{array}$ & 2,837 & 0,031 * & 1,308 & 0,276 & 0,939 & 0,447 & 3,512 & $0,035^{*}$ & 0,091 & 0,965 \\
\hline $\begin{array}{l}\text { Types } \\
\text { of } \\
\text { beha- } \\
\text { viour }\end{array}$ & 2,306 & 0,067 & 1,332 & 0,267 & 1,689 & 0,163 & 3,612 & 0,032 * & 1,129 & 0,343 \\
\hline
\end{tabular}

${ }^{*} \mathrm{p}<0,05$
Table 3 indicates that there is a significant difference in the perceptions of employees varying in age and race regarding the occurrence of levels of interaction and appearance and personality in determining the prevalence and nature of sexual harassment. Marital status, tenure and education do not influence perceptions of the key dimensions determining the prevalence and nature of sexual harassment. The implication is that employees varying in marital status, tenure and education have the same perception of the dimensions used to determine the prevalence and nature of sexual harassment. Hence, hypothesis 2 may only be partially accepted. In the sex scandal that put Toyota in the tabloids, the victim felt that her boss behaved the way he did because she is Japanese. She said "growing up in Japan, you will see discriminatory behavior against women all the time" and added that this is an underlying culture in the society which reflects in the workplace as well (Kurylko, 2006). Before Japan's Equal Employment Opportunity Law made its debut in 1986, sexual harassment in this male-dominated society was rampant. Victims had no legal recourse, and the public ignored the problem. Today, this has changed. The law required companies to organise in-house training seminars to increase the awareness of sexual harassment in the workplace. Although the law was widely criticized as being toothless because it carried no penalties for violations, awareness of the issue certainly increased. Today government is studying proposals to strengthen the law and companies are required to take preventative measures (Treece, 2006).

TABLE 4

T-Test - Biographical data AND Dimensions OF THE STUDY USED TO DETERMINE THE PREVALENCE AND NATURE OF SEXUAL HARASSMENT

\begin{tabular}{lcccc}
\hline Variable & \multicolumn{2}{c}{ Job Status } & \multicolumn{2}{c}{ Gender } \\
\hline Supervisory relations & $\mathbf{T}$ & $\mathbf{P}$ & $\mathbf{t}$ & $\mathbf{p}$ \\
Levels of interaction & 9,302 & $0,000^{*}$ & 0,147 & 0,702 \\
Appearance and personality & 6,178 & $0,003^{*}$ & 2,401 & 0,126 \\
Types of behaviour & 6,609 & $0,002 *$ & 0,532 & 0,468 \\
\hline
\end{tabular}

${ }^{*} p<0,05$

$* * \mathrm{p}<0,05$

Table 4 indicates that there is a significant difference in the perceptions of employees varying in job status regarding all four key dimensions used to determine the prevalence and nature of sexual harassment. Gender, however, does not influence perceptions of the key dimensions determining sexual harassment. The implication is that males and females have the same perception of the dimensions used to determine the prevalence and nature of sexual harassment. Hence, hypothesis 2 may only be partially accepted.

\section{Hypothesis 3}

The key dimensions of the study (supervisory relations, levels of interaction, appearance and personality, types of behaviour) significantly account for the variance in determining the prevalence and nature of sexual harassment in the workplace (Table 5).

Table 5 indicates that the four dimensions of the study significantly account for $90.5 \%$ (Adjusted $\mathrm{R}$ Square) of the variance in determining the prevalence and nature of sexual harassment at the workplace. The remaining 9.5\% could be attributed to factors that lie beyond the jurisdiction of this study. 
TABLE 5

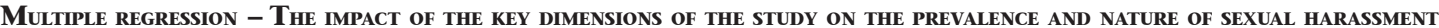

\begin{tabular}{|c|c|c|c|c|c|c|c|c|c|}
\hline \multicolumn{10}{|c|}{ Multiple Regression: Model Summary } \\
\hline \multirow[b]{2}{*}{ Model } & \multirow[b]{2}{*}{$\mathrm{R}$} & \multirow[b]{2}{*}{ R Square } & \multirow[b]{2}{*}{$\begin{array}{l}\text { Adjusted R } \\
\text { Square }\end{array}$} & \multirow[b]{2}{*}{$\begin{array}{l}\text { Std. Error of } \\
\text { estimate }\end{array}$} & \multicolumn{5}{|c|}{ Change Statistics } \\
\hline & & & & & $\begin{array}{l}\text { R Square } \\
\text { Change }\end{array}$ & F Change & Df1 & df2 & Sig. F. Change \\
\hline 1 & 0,954 & 0,910 & 0,905 & 0,671 & 0,910 & 177,464 & 4 & 71 & 0,000 \\
\hline \multicolumn{10}{|c|}{ Coefficients } \\
\hline Model & & & & \multicolumn{2}{|c|}{$\begin{array}{c}\text { Standardised Coefficients } \\
\text { Beta }\end{array}$} & \multicolumn{2}{|c|}{$\mathrm{T}$} & \multicolumn{2}{|r|}{ Sig, } \\
\hline \multicolumn{3}{|c|}{ Supervisory relations } & & \multicolumn{2}{|c|}{$-0,252$} & \multicolumn{2}{|c|}{$-2,620$} & \multicolumn{2}{|r|}{0,011} \\
\hline \multicolumn{3}{|c|}{ Levels of interaction } & & \multicolumn{2}{|c|}{0,561} & \multicolumn{2}{|c|}{1,985} & \multicolumn{2}{|r|}{0,050} \\
\hline \multicolumn{3}{|c|}{ Appearance and personality } & & \multicolumn{2}{|c|}{$-0,408$} & \multicolumn{2}{|c|}{$-2,467$} & \multicolumn{2}{|r|}{0,016} \\
\hline \multicolumn{3}{|c|}{ Types of behaviour } & & \multicolumn{2}{|c|}{1,019} & \multicolumn{2}{|c|}{4,094} & \multicolumn{2}{|r|}{0,000} \\
\hline
\end{tabular}

Table 5 reflects that, although the four dimensions of the study significantly impact on the prevalence and nature of sexual harassment, they influence the dependent variable in varying degrees as indicated below in descending level of impact (based on Beta values):-

- Types of behaviour (Beta loading = 1.019)

- Levels of interaction (Beta loading =0.561)

- Appearance and personality (Beta loading $=0.408)$

- Supervisory relations (Beta loading $=0.252$ )

Hence, hypothesis 3 may not be rejected.

\section{DISCUSSION}

\section{Supervisory relations and sexual harassment}

Subjects perceived supervisory relations as ranking fourth (out of the four dimensions) in its occurrence in determining the prevalence and nature of sexual harassment. This means that supervisors are perceived, only by a few individuals, as using their power to demand sexual favours and to make unwanted sexual advances in the workplace. The results of this study indicate that the majority of the subjects (that is, over $90 \%$ in each case) disagreed that their supervisors use their power and control to demand sexual favours, to engage in sexually charged comments/gender-related insults/sexual teasing or unwanted touching, to request sexual favours in exchange for benefits and to make sexual advances. Furthermore, staff perceived supervisory relations as having the lowest level of impact on the prevalence and nature of sexual harassment. However, although this form of sexual harassment is perceived with the least degree of occurrence, the $24.2 \%$ perceived occurrence (as reflected in the frequency analyses based on means) is a significant degree in terms of sexual harassment, that infringes on employee rights, creates a hostile environment and affects productivity. According to Jackson and Newman (2004: 706), "despite the increasing number of women in the workplace and some accommodation of their needs, many women remain segregated in quintessentially 'female' occupations". Studd and Gattiker (1991), cited in Buss and Neil (1996), maintain that the preponderance of males in supervisory relations contributes to the number of organisational power cases in sexual harassment. Women are still overwhelmingly employed in positions that men manage, supervise and administer (Unit for Research and Gender Studies, 1998). The value system of a patriarchal society legitimates power and status differences between men and women, rendering women vulnerable (Welsh, 1999; Bowes-Sperry \& Tata, 1999). In the current study, job status also influenced perceptions of subjects regarding the influence of supervisory relations on the prevalence of sexual harassment. Hence, the relationship between sexual harassment and occupational sex segregation appears to be symbiotic (Jackson \& Newman, 2004). Women who depend on men for their job security are especially vulnerable to on-the-job sexual blackmail (Unit for Research \& Gender Studies, 1998). Renzetti et al. (2001) adds that women who challenge the superiority of men responsible for social, economic or organisational power over them, are visible targets for sexualised hostility.

\section{Levels of interaction and sexual harassment}

Respondents perceived the levels of interaction as ranking second (out of the four dimensions) in its occurrence in determining the prevalence and nature of sexual harassment. This means that interactions incorporating verbal and physical harassment occur to a significant degree in the workplace. In this study, whilst $70.3 \%$ of the subjects strongly disagreed and a further $18.9 \%$ disagreed that men/women in their work environment present themselves in sexually seductive ways to people of the opposite sex, $4.1 \%$ agreed/strongly agreed with this statement. The study also reflects that whilst $75.7 \%$ of the subjects disagreed that the behaviours and actions that individuals engage in are clearly suggestive to the opposite sex, $14.9 \%$ remained neutral in their response and $9.5 \%$ agreed. Likewise, $10.8 \%$ of the subjects reported that they observed verbal and physical harassment at the workplace, $8.2 \%$ agreed that there is social pressure for men/women to flirt with each other at work and, $8.2 \%$ agreed that they are aware of cases where sexual relationships were requested in the work environment. Furthermore, staff perceived levels of interaction as having the second highest level of impact on the prevalence and nature of sexual harassment. This form of sexual harassment is perceived as having a $34 \%$ occurrence rate (as reflected in the frequency analyses), which reflects a significant degree in terms of sexual harassment.

According to Renzetti et al. (2001), women building careers in male-dominated workplaces and professions have little choice but to depend on men for their training and mentoring. Thus, in workplaces where interactions have become sexualised and harassment is common, a woman's ability to obtain her own organisational authority rests in her efforts to manage not only harassment by male co-workers and supervisors but also harassment by her male subordinate. The nature of the relationship between a woman and her harasser is also important (Benson \& Thomson, 1982, cited in Renzetti et al., 2001). Evolutionary psychology's interpretation of sexual harassment is said to be supported by empirical data on the profile of the typical victims such as age and, the conditions under which they are harassed (Crouch, 2001). Skaine (1996) found that single women claimed to experience sexual harassment more often (53\%) than married women (33\%). Similarly, in the current study age, race and job status influenced perceptions of the impact of levels of interaction among males and females on sexual harassment. According to Renzetti et al. (2001), more women of colour than 
White women depend on men for job security and career advancement. A larger proportionate of women of colour support entire families on a single wage, depend on male supervisors for job security and so have fewer options for escaping their harassers (Renzetti et al., 2001).

\section{Appearance and personality and sexual harassment}

Employees in this study perceived appearance and personality as ranking first (out of the four dimensions) in its occurrence in determining the prevalence and nature of sexual harassment. This means that there are subjects who believe that sexual advances are made to attractive and seductive individuals in the workplace, to a significant degree. Wuensch and Moore (2004) reported that people perceive physically attractive people in a more positive fashion than they do physically unattractive people. Furthermore, in the current study, the frequency analyses indicate that $9.5 \%$ of the subjects agree that sex role stereotypes exist in their workplace, $6.8 \%$ believe that physical attractiveness contributes to the occurrence of sexual harassment and, $14.9 \%$ report that they are aware that sexual advances are made to physically attractive individuals (9.5\% remained neutral in this regard). Furthermore, staff perceived appearance and personality as having the third highest level of impact on the prevalence and nature of sexual harassment. This form of sexual harassment is perceived as having a $34.67 \%$ occurrence rate (as reflected in the frequency analyses), which reflects a significant degree in terms of the prevalence and nature of sexual harassment.

Research has indicated that those who have jobs where sex is commodified or where it is performed as a service, endure more sexual harassment than those who do not (Defour, 1990, cited in Renzetti et al., 2001). Waitresses, for example, who are required to wear sexually seductive uniforms, or who have been trained to flirt with their customers as part of the job, encounter sexual harassment from their supervisors and customers (Loe, 1996, cited in Renzetti et al., 2001). Malovich and Stake (1990) emphasised personality and found that women with traditional gender attitudes and high self-esteem were more tolerant of harassment and more negative towards victims than others.

Evolutionary psychology's interpretation of sexual harassment is said to be supported by empirical data on the profile of the typical victims, including features such as their age, marital status and physical attractiveness (Crouch, 2001). Target characteristics, such as, gender, age and marital status, have also been found to be associated with sexual harassment reports (Fain \& Anderton, 1987, cited in Stockdale, 1996). In the current study, age, race and job status influenced perceptions of subjects regarding the influence of appearance and personality on the prevalence of sexual harassment. Furthermore, Crouch (2001) found that young, attractive, single or divorced women are typical victims of sexual harassment. These are characteristics of desirable women from the point of view of men who are interested in either short or long term sexual relationships. Women are more likely to have negative reactions to be propositioned, and this is what evolutionary psychology predicts, since women are interested in commitment rather than casual sex (Crouch, 2001).

\section{Types of behaviour and sexual harassment}

Subjects perceived types of behaviour as ranking third (out of the four dimensions) in its occurrence in determining the prevalence and nature of sexual harassment. This means that some subjects believe that the occurrence of sexually suggestive behaviour and sexual behaviour takes place in the workplace. Although not frequent in its occurrence, the following types of behaviours have been reported to occur as presented below in descending level of perceived occurrence (based on mean responses):

- Sexually-charged jokes $($ Mean $=1.93)$

- Lewd comments $($ Mean $=1.89)$

- Gender-related insults $($ Mean $=1.84)$
- Unwanted sexual attention $($ Mean $=1.76)$

- Leering $($ Mean $=1.70)$

- Physical assault $($ Mean $=1.53$ )

- Touching of private body parts $($ Mean $=1.46)$

- Sexual favours (Mean =1.43)

- Rape/attempted rape $($ Mean $=1.39)$

- Sexual assault $($ Mean $=1.38)$

Whilst the aforementioned mean scores may seem negligible against a maximum value of 5 , its very occurrence calls for concern. Furthermore, all of the behaviours contribute to a hostile working environment and some of them are clearly illegal. Furthermore, $8.2 \%$ of the subjects reflected incidents of unwanted behaviours, $10.9 \%$ reported occurrences of sexual compliments and an equal number reported incidents of comments across genders that were meant to be insulting. Bimrose (2004) also categorizes comments that slur women generally or particular groups of women as a form of sexual harassment. Furthermore, staff perceived types of behaviour as having the highest level of impact on the prevalence and nature of sexual harassment. This form of sexual harassment is perceived as having a 33\% occurrence rate (as reflected in the frequency analyses), which reflects a significant degree in terms of the prevalence and nature of sexual harassment. Renzetti et al. (2001) outlines that crude jokes and negative comments and even malicious gossip about a person are all forms of sexual harassment.

According to Buss and Neil (1996), sexual harassment is viewed as a behavioural consequence of evolved mechanisms that differ in the minds of men and women. Studd (cited in Buss \& Neil, 1996) conducted a study and identified the type of harassment behaviour and the percentage of cases falling into each class as follows:

- offensive language and non-verbal/non-physical harassment $(12 \%)$

- sexual propositions/date requests without threats or promises $(16.3 \%)$

- sexual propositions with job-related threats/promises $(18.5 \%)$

- physical contact of a sexual nature/sexual assault (53.3\%) - only $2.2 \%$ of the cases involve sexual assault/rape (Studd, cited in Buss \& Neil, 1996).

According to researchers (Burke \& McKeen, 1992 \& Gutek, 1985, cited in Buss \& Neil, 1996), the prevalence of harassment cases involving physical contact of a sexual nature is in direct contrast of other more general studies which reflect that less forms of sexual advances in the workplace are much more common than more overt forms. However, Piotrkowski (1998) believes that current estimates may hide a more serious problem because the more impersonal or indirect forms of harassment and 'bystander' harassment have not been emphasised. This relates to the display of sexual posters, magazines and other materials in the workplace as well as types of sexual posturing or comments that are made with other women as bystanders.

Renzetti et al. (2001) maintains that when sex and sexual behaviour is part of a work group's routine, sexual harassment is likely to be as well. Some lines of work invite sexualisation more than others do and as a result, they carry a higher risk of sexual harassment as well. Once sexual behaviour becomes routine, it becomes difficult for workers to imagine their jobs without it. The pressure to exchange sexual favours for employment is demeaning, as is a sexualised joke or gag (Rutter, 1989, cited in Renzetti et al., 2001). Rutter (1989), cited in Renzetti et al., 2001) believes that a consequence of this is an erosion of trust in others, especially men. Evolutionary psychology's interpretation of sexual harassment is said to be supported by empirical data on the profile of the typical victims such as gender and, their reactions to unwanted sex (Crouch, 2001). In the current study, race and job status 
influenced perceptions of subjects regarding the influence of types of behaviour on the prevalence and nature of sexual harassment. Past experience of other forms of violence against women such as rape, battering, abuse and incest may heighten the feelings of being violated (Renzetti et al., 2001).

\section{RECOMMENDATIONS AND CONCLUSION}

The results of the study reflect that the prevalence of sexual harassment is influenced by supervisory relations, levels of interaction, appearance and personality and types of behaviour, although in varying degrees and in descending level of impact, depicted as one extends from the inner to the outer segments in Figure 3. Furthermore, the incidences of sexual harassment range, across the spectrum of behavioural patterns, from visual, verbal, written, touching, power, threats to force. Undoubtedly, these experiences can have negative and serious repercussions for the victim and the organisation. Sexual harassment exerts a significant negative impact on psychological well-being, job attitudes and work behaviours (Schneider, Swan \& Fitzgerald, 1997). Fitzgerald, Weitman, Gold and Ormerod (1988) identified a threefold categorisation of the consequences of sexual harassment to the individual, namely, psychological, health-related (for example, headaches, sleep disturbances) and job-related (reduced job satisfaction, organisational withdrawal). Furthermore, sexual harassment has the potential to lead to reduction in the ability to perform the job, resignation, transfer, demotion, loss of job, decreased job satisfaction, decreased morale, damage to interpersonal relations at work and various economic losses (Landrine \& Klonoff, 1997; Bimrose, 2004). The consequences emphasise the need to curb the prevalence of sexual harassment in the workplace. One way to accomplish this goal is to adopt strategies for the early identification and effective management of sexual harassment (Figure 3).
Figure 3 indicates that cues for the early identification of an environment of sexual harassment exists in the workplace and includes inappropriate dress, unacceptable/unprofessional behaviour, the display of visual materials that debase women/ men and jokes and sexual innuendos.

Figure 3 also suggests strategies for minimising the negative impact of types of behaviour, levels of interaction amongst employees, appearance and personality and the nature of supervisory relations on sexual harassment:-

- Types of behaviour which impacts on the prevalence and magnitude of sexual harassment can be monitored by reporting sexual harassment behaviour immediately through formal channels and by encouraging employees to emphatically express that particular behaviours/actions are unwanted.

- Certain levels of employee interaction can contribute to the occurrence of sexual harassment. Hence, the organisational culture should emphasize and impress upon employees the adherence of societal and organisational values and to enforce norms of behaviour.

- Whilst appearance and personality has been found to impact on the prevalence of sexual harassment, this can be minimised by ensuring an appropriate dress code, and by nurturing a culture of self and mutual respect demonstrated in language and behaviour.

- Supervisors can use power positions to offer subordinates privileges in various forms in exchange for sexual favours. This can be curbed by ensuring a safe and healthy work environment, by encouraging effective complaint channels beyond the supervisor (for example, appointing sexual harassment advisors), by facilitating training for sexual harassment advisors and by ensuring that supervisors do not have sole decision-making powers over promotional and salary decisions.
- Constantly monitor workplace aesthetics

- Ongoing monitoring - supervisor/sexual harassment advisors need to be vigilant \& observant - possibly conduct surveys.

- Screen/block inappropriate e-mail messages.

- Develop a suitable organisational culture: - Foster climate of dignity \& integrity.

- Take strong opposition to gender hostility \& gender discrimination by adopting anti-discriminatory practices.

- Change gender-role socialisation mentality.

- Discourage environment that equates masculinity to success \& femininity to failure \&, end gross chauvinism.

- Conduct realistic/frank appraisals of workplace cultures.

- Emphasize Standard Code of Conduct.

- Ensure effective grievance procedures.

- Adopt severe punishment for sexual harassment offenders (transfer, dismissal, criminal charge)

- Provide open channels for guidance/ counselling - inform, advise, teach, counsel, feedback \& work within systems $\&$ structures to identify gaps.

- Constantly assess numerical \& normative dominant environments.

- Provide assertiveness training, build selfconfidence of employees.

- Coach to develop appropriate skills \& strategies to empower employees to combat sexual harassment.

- Implement effective Sexual Harassment Policy (Reese \& Lindenberg, 2004).

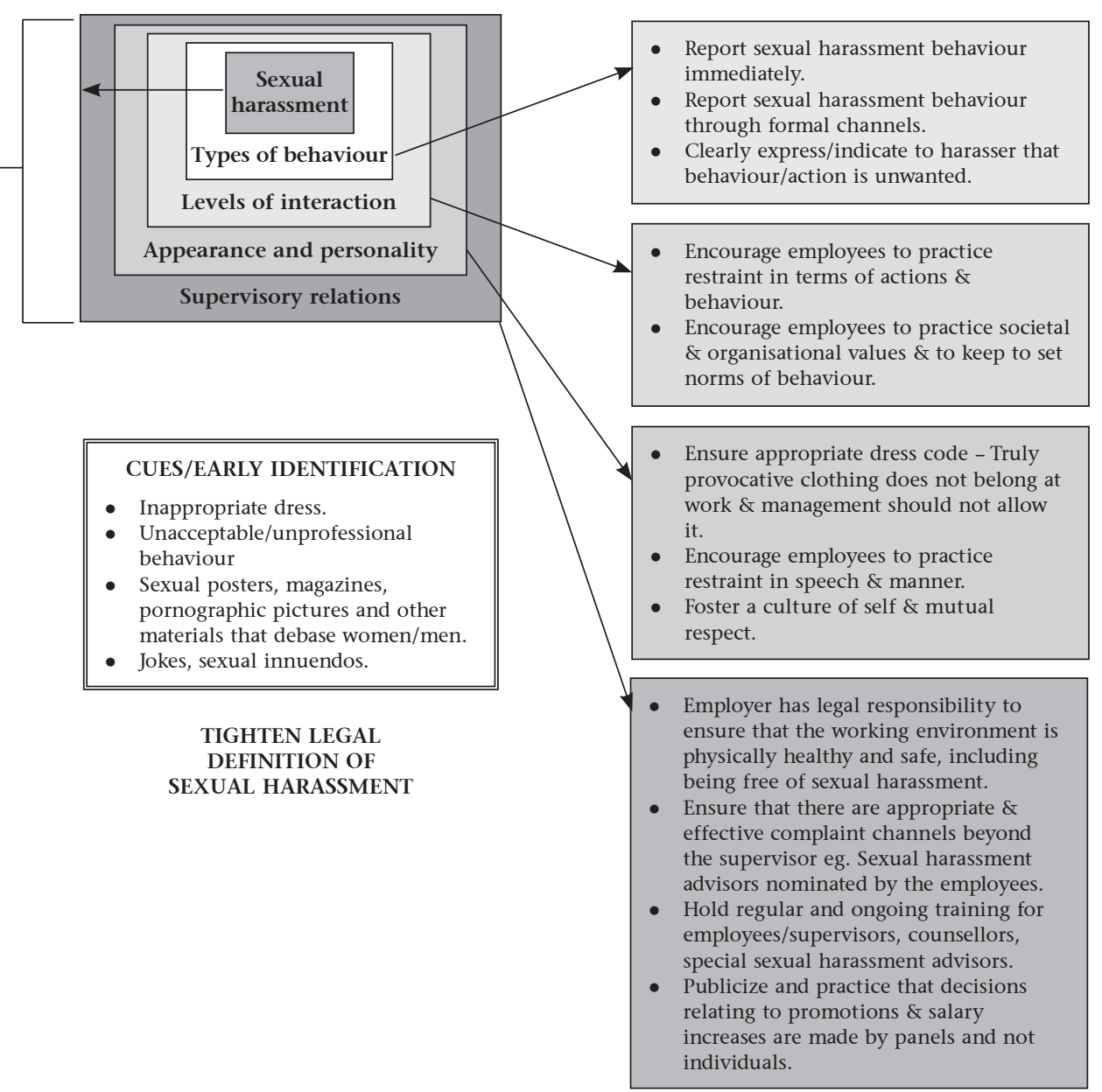

Figure 3: Model for effective management of sexual harassment in the workplace 
Whilst the prevention of sexual harassment is imperative, human behaviour is such that occurences of improper behaviour may exist. Therefore, constant monitoring of workplace aesthetics and behaviour is imperative. In addition, developing an organisational culture of integrity, opposition to gender hostility and discrimination as well as chauvinism will ensure positive workplace dynamics and will curb the prevalence of sexual harassment. Enforcing a Standard Code of Conduct whilst providing training, coaching and empowering employees to combat sexual harassment is essential to its effective management. Implementing an effective sexual harassment policy will certainly emphasize the organisation's non-tolerance for sexually related misconduct. More reactive and punitive measures would be to ensure counseling, an effective grievance procedure and severe punishment for sexual harassment offenders.

On a macro-level, the effective management of sexual harassment certainly demands a more tightened definition of sexual harassment as the current one is open to tremendous controversy.

Taking cognisance of, and adopting, the strategies discussed above and presented in Figure 3 will enable organisations to reduce, if not eliminate, the prevalence of sexual harassment such that the work environment can be a more pleasant, safe, collegial, idea generating, professional and hence, productive one.

\section{REFERENCES}

Achampong, F. (1995). Workplace sexual harassment law principles, landmark developments and framework for effective risk management. USA: Quorum Books.

Automative News. (2006). Toyota's culture proved itself in sex scandal. 15 May 2006, Database: Business Source Complete, Opinion section, 00051551, 80(6202).

Bassoon, A.C. (1999). The regulation of unfair discrimination by the Employment Equity Act 55 of 1998. The South African Mercantile Journal, 11, 240 - 249.

Bimrose, J. (2004). Sexual harassment in the workplace: an ethical dilemma for career guidance practice? British Journal of Guidance and Counselling, 32(1), 109 - 121.

Bowes-Sperry, L. \& Tata, J. (1999). A multiperspective framework of sexual harassment: Reviewing two decades of research. In Handbook of Gender and Work, edited by Gary Powell, 263 - 280. Thousand Oaks, CA: Sage Publications.

Bravo, E. \& Cassedy, E. (1992). The 9 to 5 guide to combating sexual harassment. The candid advice from 9 to 5 - The National Association of working women. USA: John Wiley and Sons.

Buss, D.M. \& Neil, M. (1996). Sex power conflict: Evolutionary and Feminist Perspectives. USA: Oxford University Press.

Carrell, M.R., Elbert, N.F., Hatfield, R.D., Grobler, P.A., Marx, M. $\&$ Van De Schyf, S. (2000). Human resource management in South Africa. South Africa: Mills Litho.

Crouch, A. (2001). Thinking about sexual harassment: A guide for the perplexed. USA: Oxford University Press.

Eberharat, L.Y. (1995). Working with groups in the workplace: Confronting sexual harassment. West Michigan: Whole Person Association Press.

Equal Opportunities Commission. (2000a). The labour market. Internet. http://www.eoc.org.uk/csengresearch (July 2003).

Equal Opportunities Commission. (2000b). Sex equality and sexual harassment. Internet. http://www.eoc.org.uk (November 2001).

Fair Employment Practices Guidelines. (2006). Single comment and gesture do not equal sexual harassment. Number 613, June 2006. Aspen Publishers.
Fitzgerald, L.F. (1993). Sexual harassment: violence against women in the workplace. American Psychologist, 48, 1070 $-1076$.

Fitzgerald, L.F., Weitman, L.M., Gold, Y. \& Ormerod, M. (1988). Academic harassment: sex and denial in scholarly garb. Psychology of Women Quarterly, 12, 329 - 340.

Gutek, B.A. \& Morasch, B. (1982). Sex Ratios, sex-role spillovers and sexual harassment of women at work. Journal of Social Issues, 38(4), $55-74$.

Jackson, R.A. \& Newman, M.A. (2004). Sexual harassment in the federal workplace revisited: Influences on sexual harassment by gender. Public Administration Review, 64(6), $705-717$

Kurylko, D.T. (2006). Sex scandal puts staid Toyota in the tabloids. Automative News, Database: Business Source Complete, 00051551, 80(6201).

Landrine, H. \& Klonoff, E.A. (1997). Discrimination again women: Prevalences, consequences and remedies. Thousand Oaks, CA: Sage Publications.

Malocich, N.J. \& Stake, J.E. (1990). Sexual harassment on campus: individual differences in attitudes and beliefs. Psychology of Women Quarterly, 1, 63 - 81.

McElroy, W. (1996). Sexual correctness: The gender feminist attack on women. USA: McFarland and Co. Inc. Publishers.

Neil, N. (2006). Hidden harassment: Law firms and disciplinary authorities look for ways to fight sexual misconduct. $A B A$ Journal, Database: Academic Search Premier, Employment Law section, 07470088, 92(3).

Piotrkowski, C.S. (1998). Gender harassment, job satisfaction, and distress among employed White and minority women. Journal of Occupational Health Psychology, 3, 33 - 43.

Renzetti, C.M., Edleson, J.L. \& Bergen, R.K. (2001). Sourcebook on violence against women. USA: Sage Publishers.

Reid, P. (2004). Opportunities for equality: A European view of the HR profession. People Management, September, 22.

Roumell, M.T. \& Danlene, O. (1999). What every manager needs to know about sexual harassment. USA: AMACON.

Schneider, K.T., Swan, S. \& Fitzgerald, L.F. (1997). Job-related and psychological effects of sexual harassment in the workplace: empirical evidence from two organisations. Journal of Applied Psychology, 82, $401-415$.

Schultz, V. (1998). Reconceptualizing sexual harassment. Yale Law Journal, 107(6), 1683 - 1805

Skaine, R. (1996). Power and gender issues in sexual dominance and harassment. USA: McFarland \& Co. Inc. Publishers.

South Africa Survey. (2001/2002). South African Institute of Race Relations. Johannesburg: South African Institute of Race Relations.

South Africa Survey. (2003/2004). South African Institute of Race Relations. Johannesburg: South African Institute of Race Relations.

Stockdale, M.S. (1996). Sexual harassment and the workplace perspectives, frontiers and response strategies: Women at work, 5(303).

Treece, J.B. (2006). Sex-harassment law violators in Japan draw light penalties. Automative News, Database: Business Source Complete, 00051551, 80(6201).

Unit for Research \& Gender Studies. (1998). Women and the law in South Africa. South Africa: University of South Africa.

USA Today. (2006). Toyota to review conduct policies. Database: Academic Search Premier, Money section, 10 May 2006, 07347456.

Welsh, S. (1999). Gender and sexual harassment. Annual Review of Sociology, 25, $169-190$.

Wuensch, K.L. \& Moore, C.H. (2004). Effects of physical attractiveness on evaluations of a male employee's allegation of sexual harassment by his female employer. The Journal of Social Psychology, 144(2), 207 - 217. 